IZA DP No. 55

Value-added Tax versus Social Security

Contributions

Laszlo Goerke

August 1999 


\title{
Value-added Tax versus Social Security Contributions
}

\author{
Laszlo Goerke \\ Universität Konstanz
}

\section{Discussion Paper No. 55 \\ August 1999}

\author{
IZA \\ P.O. Box 7240 \\ D-53072 Bonn \\ Germany \\ Tel.: +49-228-3894-0 \\ Fax: +49-228-3894-210 \\ Email: iza@iza.org
}

This Discussion Paper is issued within the framework of IZA's research area The Welfare State and Labor Markets. Any opinions expressed here are those of the author(s) and not those of the institute. Research disseminated by IZA may include views on policy, but the institute itself takes no institutional policy positions.

The Institute for the Study of Labor (IZA) in Bonn is a local and virtual international research center and a place of communication between science, politics and business. IZA is an independent, nonprofit limited liability company (Gesellschaft mit beschränkter Haftung) supported by the Deutsche Post AG. The center is associated with the University of Bonn and offers a stimulating research environment through its research networks, research support, and visitors and doctoral programs. IZA engages in (i) original and internationally competitive research in all fields of labor economics, (ii) development of policy concepts, and (iii) dissemination of research results and concepts to the interested public. The current research program deals with (1) mobility and flexibility of labor markets, (2) internationalization of labor markets and European integration, (3) the welfare state and labor markets, (4) labor markets in transition, (5) the future of work, and (6) general labor economics.

IZA Discussion Papers often represent preliminary work and are circulated to encourage discussion. Citation of such a paper should account for its provisional character. 
IZA Discussion Paper No. 55

August 1999

\title{
ABSTRACT
}

\section{Value-added Tax versus Social Security Contributions}

In order to alleviate unemployment it is often recommended to reduce social security contributions (SSC) and to compensate for the ensuing loss in revenues by a rise in the value-added tax (VAT). Assuming unemployment to be caused by efficiency wages, it is shown that a balanced-budget shift from a payroll tax to a VAT will increase employment if the rise in the VAT does not alter consumer prices. If the effects of a shift from SSC to the VAT on the worker's effort are neutralised, for example, by imposing a constant wedge, the employment impact will depend on the nature of the unemployment compensation system.

JEL Classification: H 24, H 25, J 32, J 41

Keywords: Efficiency wages, social security contributions, unemployment, value-added tax

\author{
Laszlo Goerke \\ Universität Konstanz \\ Fakultät für Wirtschaftswissenschaften und Statistik \\ Fach D 138 \\ D - 78457 Konstanz \\ Tel.: $+49753188-2137$ \\ Fax: +49 753188-3130 \\ email: Laszlo.Goerke@uni-konstanz.de
}

\footnotetext{
*I am grateful for helpful and very constructive comments by anonymous referees and by participants at the IZA research seminar in Bonn. The usual disclaimer applies. Forthcoming: Jahrbücher für Nationalökonomie und Statistik
} 


\section{Introduction}

Social insurance systems are often financed by income dependent contributions. In general, these contributions are shared by employers and employees. Since social security contributions (SSC) drive a wedge between labour costs and disposable income, their increase has been blamed for the rise in unemployment, especially in Europe (OECD 1995, EU 1993). 1 Thus, proposals have been put forward to decrease SSC. To avoid budget deficits, expenditure can be reduced. Alternatively, proposals to lower SSC are combined with the request for higher tax rates, in particular of the value-added tax (VAT). This shift of the fiscal burden is argued to promote employment. A recent example of such a tax reform can be found in Germany, where the VAT was raised in 1998 to prevent additional increases in SSC for old age pensions.

Using an efficiency wage model of unemployment, it is demonstrated below that the prediction of an employment enhancing, balanced-budget shift from employers' SSC to a VAT requires the VAT not to be shifted forward into consumer prices. If the effects of a shift from SSC to the VAT on the worker's effort are neutralised, for example, by imposing a constant wedge, the employment impact will depend on the nature of the unemployment compensation system. However, in general, substituting a VAT for SSC has uncertain employment consequences. In the next section, the stage is set for the formal analysis based on the model which is set out in Section 3. In Section 4, the wage and employment consequences of an increase in SSC and in the VAT are analysed, while in Section 5 various fiscal reforms are investigated. In Section 6, the findings are summarised and limitations of the analysis are discussed.

\section{A Review of the Issues}

Analyses of tax reforms which are intended to promote employment need to be based on a theoretical framework which explicitly allows for unemployment. The microeconomic models currently dominating the debate about unemployment are search models, union-firm bargaining approaches and efficiency wage models (Pissarides 1998). Thus far, no consensus has arisen as to which of the models can explain unemployment most adequately. Most empirical investigations on the impact of trade unions show that unions raise wages above the competitive level and, hence, cause unemployment (Pencavel 1991). The evidence on search models also suggests that these approaches can contribute to an explanation of unemployment (Devine and Kiefer 1991). Efficiency wage models are notoriously difficult to test. However,

\footnotetext{
1 "Evidence that taxes on labour increase wage pressure and thereby increase unemployment (at least in the shortrun) is, with some exceptions, reasonably convincing and in some countries, the increase in the tax wedge may have accounted for a significant proportion of the increase in unemployment." (OECD 1995, 68).
} 
the evidence for numerous countries, based on a multitude of approaches, suggests that wages are employed to "recruit, retain, and motivate" (Layard et al. 1991) and that the twofold function of wages also brings about unemployment. Given the competing explanations of unemployment, it is advisable to develop policy proposals which yield qualitatively similar predictions, irrespective of the model employed. In this paper, the unemployment consequences of a shift from SSC to a VAT are analysed in a shirking model of efficiency wages. The conditions for positive employment effects which are derived for this model of unemployment can provide a guideline or evaluation criterion for the results derived in the context of other explanations of unemployment.

Tax reforms involving a variation in SSC and a VAT have, thus far, not been investigated comprehensively in models of imperfectly competitive labour markets. In a wage bargaining model in which consumption taxes are born by consumers, and union utility is linear in the net real wage, Pflüger (1997) shows that a shift from payroll or linear income taxes to consumption taxes will reduce unemployment if benefits are not taxed. This prediction is due to the assumption that the consumption tax does not affect the utility differential resulting from obtaining the wage or from income while being unemployed. This characteristic of Pflüger's model points to an important feature, an issue initially raised by Pemberton (1992) and also emphasised by Bovenberg and van der Ploeg (1994) or Koskela and Schöb (1999) in the analysis of other tax reforms than the one investigated here: The employment effects of tax policy can be determined by the assumptions pertaining to the impact of tax and price changes on the alternative income. Since prices might change with variations in the VAT, the analysis of tax reforms involving the VAT must take this issue into account. Moreover, Pissarides (1998) has shown that the employment effects of restructuring labour taxation can depend crucially on whether unemployment benefits are given by a real replacement rate or real benefits. Hence, the alternative income is approximated by payments to an unemployed worker. Furthermore, making use of the findings by Pemberton (1992) and Pissarides (1998), a distinction is made between 4 different benefit systems, namely, (a) nominally fixed benefits, (b) a nominally fixed replacement rate, (c) constant real benefits, and (d) a fixed real replacement rate. In addition, it is well known from the analysis of tax policy in imperfect labour markets that employment not only depends on tax levels but also on the tax structure. In the context of SSC, therefore, contributions by employers and by employees are distinguished in the subsequent analysis.

While Pflüger's (1997) analysis for a collective bargaining approach provides some guidelines as to the determinants of the employment effects of a substitution of the VAT for SSC, in the context of efficiency wage approaches, this issue has not been dealt with in depth. Hoon and Phelps (1996), for example, analyse a dynamic turnover model and find, employing logarithmic utility and Cobb-Douglas production functions and a zero profit constraint, that a shift 
from payroll taxes to a VAT reduces unemployment in a closed economy and in a two-country world with capital mobility. Unfortunately, the unemployment benefit system is neglected in Hoon and Phelps (1996) and their results are not necessarily driven by labour market adjustments. Zoega (1997) investigates an increase in public consumption which is financed by higher payroll or consumption taxes in a dynamic shirking framework. However, a tax reform is not considered. The remaining sections of this paper attempt to fill the gap which these studies leave.

\section{The Shirking Economy}

Suppose that employees can shirk and that firms, being able to set wages and employment unilaterally, attempt to deter employees from shirking by paying wages in excess of the full employment level. Employees then face a trade-off between working hard and having a lower probability of becoming - and perhaps remaining - unemployed, and working less hard and having a higher probability of unemployment. In contrast to the pioneering paper by Shapiro and Stiglitz (1984), it is assumed here that effort is a continuous variable, employing a framework developed by Pisauro (1991).

\subsection{Effort Function}

The employees' utility $\mu$ is additively separable in the utility from net real income and effort e. Utility $\mu^{\mathrm{e}}$ of an employed worker can then be depicted as $\mu^{\mathrm{e}}=\mathrm{v}[(\mathrm{w}-\tau \mathrm{w}) / \mathrm{p}]-\mathrm{e}$, where $\mathrm{v}(\cdot)$ is a strictly concave function of net real income $\left(v^{\prime}>0, v^{\prime \prime}<0, v(0)=0\right)$, w the gross wage, $\tau$ w the employees' SSC, $0 \leq \tau<1$, and $\mathrm{p}$ the consumer price index 2 The disutility of effort is denoted by e. More specifically, e is the fraction of the working time during which effort is supplied. If working time is fixed and normalised to unity, e $\in[0,1]$ will hold and shirking will imply e < 1. An unemployed worker obtains utility $\mu^{\mathrm{u}}$ from unemployment benefits because no effort is required when unemployed. The participation constraint requires $\mu^{\mathrm{e}}>\mu^{\mathrm{u}}$.

Employees choose an optimal level of effort, given the wage offered by the firm. This relationship defines the effort function which the company takes into account when maximising profits. A worker who shirks is detected with probability $D$. Detection implies the immediate loss of the job. With a probability $\mathrm{u}$, where $\mathrm{u}$ is the aggregate unemployment rate, the worker who has been fired finds no new job and receives unemployment benefits. With probability (1 - u) s/he obtains another job in which the same wage as before is paid, and the same effort is

${ }^{2}$ By defining (indirect) utility over the net wage, this framework obviously does not allow for saving. 
put forward. For simplicity, there is no discounting and a repeated risk of becoming unemployed is not taken into account. Bhus, expected utility EU of a worker is given by:

$$
E U=\mu^{e}(1-D)+D\left\lfloor(1-u) \mu^{e}+u \mu^{u}\right\rfloor
$$

Let the probability $D$ of being caught shirking be a linear function of the time an employee has not exerted effort. For a parameter $d$, capturing the exogenously determined effectiveness of monitoring, the detection probability is given by $D=d(1-\mathrm{e})$. Substituting in (1), maximising with respect to effort e for a given wage, and solving for e yields:

$$
e=0.5\left[v\left(\frac{w-\tau w}{p}\right)-\mu^{u}+1-\frac{1}{u d}\right]
$$

Hence, effort is increasing with the nominal and the real wage, with the unemployment rate $u$ and it shrinks with the utility from being unemployed $\mu^{\mathrm{u}}$. Moreover, effort is additively separable in utility from income and unemployment. These features are important for the derivation of results. However, the specific form of the effort function (2) is not required.

\subsection{Unemployment Benefits}

For the results to be derived below, the definition of the utility from being unemployed can be of great importance. For simplicity, the subsequent discussion about the alternative income is phrased in terms of unemployment benefits. However, it applies equally to other assistance payment systems. Since no effort is required when being unemployed, the utility from having no job is defined by the utility which results from obtaining real unemployment compensation $\gamma$. Assume that unemployment benefits are not subject to SSC. To ease notation denote the utility from real unemployment benefits by $\tilde{v}=\tilde{v}(\gamma)$. One possibility of modelling real unemployment benefits $\gamma$ is to assume that benefits $b$ are fixed in nominal terms. The utility from being unemployed $\tilde{v}$ is then defined by $\tilde{v}(\gamma)$, where $\gamma=b / p$, since the real value $\gamma$ of nominal benefits $b$ results from dividing $b$ by the consumer price index $p$. In this 'nominal benefit' system any change in the level of prices automatically alters the utility from obtaining unemployment compensation. An alternative assumption is that the nominal replacement rate is constant, such that real benefits $\gamma$ are given by $\gamma=\beta \mathrm{w} / \mathrm{p}, 0<\beta<1$ (called 'nominal replacement rate'). In this case, not only changes in the price level but also variations in wages alter the utility resulting from unemployment compensation. In contrast to nominal benefit systems, it is also feasible that benefits are defined in real terms. Then, a constant real benefit level can be assumed

and

\footnotetext{
${ }^{3}$ See Pisauro (1991) for details of the argument, or Chang (1995), Goerke (1997, 1999a), and Lin and Lai (1997) who employ the same model. The assumption that the future is not discounted is consistent with defining utility over wages only, instead of savings and consumption. The issue of whether unemployment might result from intertemporal substitution between work and leisure can, thus, not be tackled in this framework.
} 
$\gamma=(\mathrm{bp}) / \mathrm{p}=\mathrm{b}$ holds ('real benefits'). Finally, the replacement rate might be fixed in real terms and $\gamma=\beta \mathrm{w}$ applies ('real replacement rate'). The 'real' benefit variants can be an adequate description if unemployment compensation is (periodically) adjusted to changes in the price level p. Otherwise, the nominal variants are more appropriate.

\subsection{Firms}

There is a given number of identical firms in the economy with a constant capital stock producing a single good. Capital can, therefore, be omitted from the further analysis. Firms are characterised by a strictly concave production function $\mathrm{f}$ ( $\mathrm{f}^{\prime}>0, \mathrm{f}^{\prime \prime}<0, \mathrm{f}(0)=0$ ) with efficiency units of labour as argument. Hence, there is no distinction between the productivity and the effort effects of changes in e. Labour costs are equal to the product of the number of employees $n$ and the wage w plus the payroll tax $n t w, t \geq 0$ (alternatively referred to as SSC by employers). All firms can sell the homogeneous product for a given price which is normalised to unity in the absence of taxes. However, firms have to pay a tax $r$ per unit of revenue or output, $0 \leq \mathrm{r}<1$, which all firms can shift forward into output prices - or pass on to consumers - to the same degree. Therefore, the payroll tax and the tax on revenues are fundamentally different from an analytical perspective insofar as that the latter can be shifted forward into prices whereas the former cannot.

The extent of forward shifting of the tax on revenues is determined exogenously and measured by the parameter $s, 0 \leq s \leq 1$. Therefore, net revenues $\eta$ per unit of output are given by $\eta \equiv 1-r(1-s)>0$. From a microeconomic perspective, $s$ indicates the relationship between the elasticities of supply and demand of the output good; the more elastic demand being for a given (positive) elasticity of supply, the less the possibility of forward shifting, i.e. the lower $\mathrm{s}$ is. From a macroeconomic point of view, a high value of s could, for example, be due to a favourable state of the trade cycle or a lax stance of monetary policy. Alternatively, a higher value of s could indicate a longer term perspective since the long-run zero profit constraint ensures that companies can only remain in the market if they do not bear the tax burden. Moreover, it can be argued that the extent of shifting of the tax on revenues depends on the other taxes which are altered as a compensation. Assume, for example, that the payroll tax is lowered and the tax on revenues is raised in such a way as to leave the firms' tax burden unchanged. Then, firms may not attempt to shift forward the rise in the tax on revenues at all. 4 Thus, for such a reform of the fiscal system, special attention is paid to the case of $s=0$. Moreover, the extent of shifting might be influenced by the sectoral composition in a multi-good economy. Since these aspects cannot be captured in their entirety without specifying a model of output price determination, the parametric treatment represents a 'second-best' approach

\footnotetext{
${ }^{4}$ I owe this point to an anonymous referee.
} 
which provides for a general analysis and allows for the derivation of conditions under which a substitution of one tax for another promotes employment.

Since labour is the only (variable) input and firms are assumed to sell their entire output, the tax on revenues $r$ can be interpreted as a VAT. Obviously, in a single good economy there is only one VAT rate. If all other determinants of consumer prices $\mathrm{p}$ than the VAT rate are constant, $\mathrm{p}$ will be given by $\mathrm{p}=1+\mathrm{sr}$. Profits per firm $\Pi$ are defined by:

$$
\Pi=(1-r(1-s)) f(e n)-n w(1+t)
$$

The firm sets an optimal wage $w$ and chooses employment $n$, given the efficiency wage (cf. Shapiro and Stiglitz 1984). This implies the following first-order conditions:

$$
\begin{aligned}
& \Pi_{\mathrm{w}}=\mathrm{n}\left[\eta \mathrm{f}^{\prime} \mathrm{e}_{\mathrm{w}}-(1+\mathrm{t})\right]=0 \\
& \Pi_{\mathrm{n}}=\eta \mathrm{f}^{\prime} \mathrm{e}-\mathrm{w}(1+\mathrm{t})=0
\end{aligned}
$$

According to (3), marginal effort $\mathrm{e}_{\mathrm{W}}$ must be positive, irrespective of the benefit system, for the firm's maximisation problem to have an interior solution. The combination of (3) and (4) yields a Solow-condition (Solow 1979) or a shirking constraint $\Psi$ :

$$
\Psi \equiv \mathrm{e}_{\mathrm{W}} \mathrm{W}-\mathrm{e}=0
$$

Since the second-order condition for the firm's profit maximum requires $\mathrm{e}_{\mathrm{WW}}<0$, the shirking constraint declines with the wage $\left(\Psi_{\mathrm{W}}<0\right)$. Moreover, $\Psi_{\mathrm{u}}<0$ holds because $\mathrm{e}_{\mathrm{W}}$ is independent of the unemployment rate while effort e increases with $u$. The firm's optimal level of employment declines with the wage w while it increases with effort for ( $f$ "en $\left.+f^{\prime}\right)>0$ which, henceforth, is assumed to be the case 5 Aggregate employment $\mathrm{N}$ is the product of the number of firms $\rho$ and employment per firm $n$.

$$
\Phi \equiv \mathrm{N}-\rho \mathrm{n}(\mathrm{w}, \mathrm{e}, \mathrm{r}, \mathrm{t})=0
$$

Subsequently, $\Phi$ is referred to as the aggregate labour demand curve. For a labour supply of given size normalised to unity, the level or rate of unemployment $\mathrm{u}$ is defined by $\mathrm{u}=1-\mathrm{N}$. $\Phi$

\footnotetext{
${ }^{5}$ For expositional convenience, employment $\mathrm{n}$ is treated as a function of effort $\mathrm{e}$, although $\mathrm{n}$ is actually a function of the arguments of e. However, allowing for $n=n(e, \ldots)$ simplifies the subsequent presentation. The labour demand curve in efficiency wage models can be backward bending (Fehr 1991). However, it definitely has a negative slope in this model for a wage not below the efficiency wage. Using equation (3), one obtains from (4), that is, evaluating $\mathrm{n}_{\mathrm{W}}$ at the optimal wage:

$\mathrm{n}_{\mathrm{W}}=\frac{1+\mathrm{t}}{\eta \mathrm{f}^{\prime \prime} \mathrm{e}^{2}}-\frac{\eta\left(\mathrm{f}^{\prime}+\mathrm{f}^{\prime \prime} \mathrm{en}\right)}{\eta \mathrm{f}^{\prime \prime} \mathrm{e}^{2}} \mathrm{e}_{\mathrm{W}}=-\frac{\mathrm{ne}_{\mathrm{W}}}{\mathrm{e}}<0$

The requirement $\mathrm{f}^{\text {"en }}+\mathrm{f}^{\prime}>0$ holds, inter alia, for a Cobb-Douglas production function. More generally, in a model in which capital is determined endogenously it implies that the elasticity of substitution between labour and capital be not too low (cf. Pisauro 1991).
} 
increases with the wage $\left(\Phi_{\mathrm{W}}>0\right)$, while $\Phi_{\mathrm{u}}=-\left(1+\rho \mathrm{n}_{\mathrm{e}} \mathrm{e}_{\mathrm{u}}\right)<0$ holds. Equations (5) and (6) define the equilibrium of the economy, which is taken to imply shirking.

\section{Changes in Tax Rates}

As a preliminary step, increases in tax rates are analysed. For a given wage, the change in employment per firm $n$ owing to a rise in either of the tax rates is given by:

$$
\begin{gathered}
\mathrm{n}_{\mathrm{t}}=-\frac{\Pi_{\mathrm{nt}}}{\Pi_{\mathrm{nn}}}=\frac{\mathrm{w}}{\eta \mathrm{f}^{\prime \prime} \mathrm{e}^{2}}<0 \\
\mathrm{n}_{\mathrm{r}}=\frac{\mathrm{f}^{\prime} \mathrm{e}(1-\mathrm{s})}{\eta \mathrm{f}^{\prime \prime} \mathrm{e}^{2}}-\frac{\mathrm{f}^{\prime \prime} \mathrm{en}+\mathrm{f}^{\prime}}{\mathrm{f}^{\prime \prime} \mathrm{e}^{2}} \mathrm{e}_{\mathrm{r}}=\mathrm{n}_{\mathrm{t}} \mathrm{A}+\mathrm{n}_{\mathrm{e}} \mathrm{e}_{\mathrm{r}} \\
\mathrm{n}_{\tau}=\mathrm{n}_{\mathrm{e}} \mathrm{e}_{\tau}<0
\end{gathered}
$$

where $A \equiv(1-s)(1+t) / \eta \geq 0$ and $e_{\tau}=-0.5 v^{\prime} w / p<0$. Thus, an increase in SSC paid either by employers or employees reduces employment per firm, while the impact of a higher VAT depends on the impact of this tax increase on effort. Utilising these findings, the system of the two equations (5) and (6) can be employed to predict the wage and unemployment effects of increases in the payroll tax $\mathrm{t}$, the employees' SSC $\tau$ and in the VAT rate $\mathrm{r}$. For a given number of firms, the value of $\rho$ does not alter these effects and is subsequently set equal to unity.

$$
\begin{aligned}
\frac{\mathrm{du}}{\mathrm{dt}} \equiv \mathrm{u}_{\mathrm{t}} & =\frac{\mathrm{e}_{\mathrm{WW}} \mathrm{wn}_{\mathrm{t}}}{\mathrm{D}}>0, \text { where } \mathrm{D}=\Psi_{\mathrm{W}} \Phi_{\mathrm{u}}-\Phi_{\mathrm{W}} \Psi_{\mathrm{u}}>0 \\
\mathrm{w}_{\mathrm{t}} & =\frac{\mathrm{n}_{\mathrm{t}} \mathrm{e}_{\mathrm{u}}}{\mathrm{D}}<0
\end{aligned}
$$

A rise in the payroll tax $t$ does not affect the efficiency wage as defined by equation (5) for a given level of unemployment $\mathrm{u}$, since the costs of raising either employment $\mathrm{n}$ or the wage $\mathrm{w}$ by one unit are both increased by $(1+\mathrm{t})$ units. However, as optimal employment declines with labour costs for a given level of effort, employment shrinks with a rise in the payroll tax $t$. The resulting increase in unemployment allows the firms to reduce the efficiency wage.6

The impact of a rise in the employees' SSC $\tau$ is given by:

$$
\begin{aligned}
& \mathrm{u}_{\tau}=\frac{\mathrm{e}_{\mathrm{WW}} \mathrm{wn}_{\mathrm{e}} \mathrm{e}_{\tau}-\mathrm{n}_{\mathrm{W}}\left(\mathrm{e}_{\mathrm{w} \tau} \mathrm{w}-\mathrm{e}_{\tau}\right)}{\mathrm{D}}>0 \\
& \mathrm{w}_{\tau}=\frac{\left(\mathrm{e}_{\mathrm{w} \tau} \mathrm{w}-\mathrm{e}_{\tau}\right)\left(1+\mathrm{n}_{\mathrm{e}} \mathrm{e}_{\mathrm{u}}\right)+\mathrm{n}_{\mathrm{e}} \mathrm{e}_{\tau} \mathrm{e}_{\mathrm{u}}}{\mathrm{D}}
\end{aligned}
$$

\footnotetext{
${ }^{6}$ See, inter alia, Pisauro (1991), Carter (1992), Petrucci (1994), and Goerke (1997, 1999a).
} 
A rise in $\tau$ reduces the workers' net income and, hence, their effort for a given wage since unemployment benefits are not altered by variations in $\tau$. Each company reacts to this alteration in the trade-off between higher wages and higher effort by a rise in the wage since $\left(\mathrm{e}_{\mathrm{W}} \tau \mathrm{W}\right.$ $\mathrm{e}_{\tau}$ ) >0 (see appendix I). Therefore, greater unemployment ensues. The increase in unemployment mitigates the wage change. Thus, the wage impact of a rise in the employees' SSC $\tau$, which is equivalent to a rise in a linear income tax rate, is ambiguous (cf. Hoel 1990 or Goerke 1999a).

The effects of a rise in the VAT rate $r$ are defined by:

$$
\begin{gathered}
u_{r}=\frac{e_{w w} w n_{r}-n_{W}\left(e_{w r} w-e_{r}\right)}{D}=A u_{t}+\frac{e_{w w} n_{e} e_{r}-n_{W}\left(e_{w r} w-e_{r}\right)}{D} \\
w_{r}=\frac{\left(e_{w r} w-e_{r}\right)\left(1+n_{e} e_{u}\right)+n_{r} e_{u}}{D}
\end{gathered}
$$

The increase in $r$ reduces the net income from working and will also diminish net unemployment benefits if they are not indexed to the consumer price index p. Hence, the alteration in the utility differential resulting from working and shirking changes in an ambiguous way for nominal benefits. Therefore, the optimal wage defined by the shirking constraint might change in either way (see appendix I). Moreover, the direct, negative employment consequences of an increase in the VAT which is not shifted forward completely into prices imply a reduction in wages. Thus, the wage change due to a rise in $r$ is ambiguous. The unemployment consequences of a rise in the VAT are indeterminate for nominal benefit systems. However, if the VAT is not shifted forward at all $(\mathrm{s}=0),\left(\mathrm{e}_{\mathrm{wr}} \mathrm{W}-\mathrm{e}_{\mathrm{r}}\right)=\mathrm{e}_{\mathrm{r}}=0$ will apply and, therefore, employment will decline in the presence of a nominal benefit system. For real benefit systems $\left(\mathrm{e}_{\mathrm{wr}} \mathrm{W}-\mathrm{e}_{\mathrm{r}}\right) \geq 0$ and $\mathrm{e}_{\mathrm{r}} \leq 0$ hold and unemployment unambiguously rises owing to an increase in the VAT. This is so because, first, the efficiency wage has to be increased for $s>0$ and, second, labour demand falls, irrespective of the degree of shifting.

The above analysis demonstrates that an unambiguous decline in unemployment cannot be achieved by an increase in any of the three tax rates under consideration. Thus, there is no a priori obvious variation of taxes which creates additional jobs and retains a balanced budget.

\section{Fiscal Reforms}

In this section, three types of fiscal reforms are evaluated. First, the government is assumed to raise the VAT and to lower employers' SSC or payroll taxes while preserving a balanced budget. The employment effect of such a reform will only be unambiguously positive if the VAT is not shifted forward. Second, if employees' SSC are altered, even the restrictive assumption of no forward shifting of the VAT will, in general, no longer suffice to determine 
the employment effects of a balanced-budget reform. However, if the tax wedge is held constant, employment enhancing tax reforms will become feasible. Third, a shift from SSC shared equally by employers and employees to the VAT is investigated.

\subsection{Payroll Taxes versus VAT}

Suppose the government decides to lower the payroll tax $t$, that is the employers' SSC, and at the same time to raise the VAT rate $r$ by such an amount as to preserve the government's budget balance. The ensuing change in unemployment is given by:

$$
\frac{d u}{d r}{ }_{t=t(r)}=\frac{1}{D}\left\{e_{w w} w\left[n_{r}+n_{t} \frac{d t}{d r}\right]-n_{w}\left(e_{w r} w-e_{r}\right)\right\}
$$

The sign of the term in square brackets in (16) depends on the extent to which a rise in $r$ induces a reduction in $\mathrm{t}$. This reduction in $\mathrm{t}$ is determined by the requirement of budget neutrality, haven taken into account the adjustments of wages and employment. The government's revenues consist of receipts from the payroll tax twN, employees' SSC $\tau_{\mathrm{wN}}$, and the VAT, namely rf. The only expenditure results from the benefits for unemployed people $\hat{\gamma}, \hat{\gamma} \equiv \gamma p$, since $\hat{\gamma}$ depicts the nominal value of benefits to unemployed workers who derive (indirect) utility from real benefits $\gamma$. TThe budget $B$ is given by $B=w(1-u)(t+\tau)+r f-u \hat{\gamma}$. Since $N=$ $1-u$, the change in $B$ due to a rise in $i=t, \tau$, or $r$ is defined by:

$$
\begin{aligned}
& \mathrm{B}_{\mathrm{i}}=\mathrm{w}_{\mathrm{i}} \mathrm{N}(\mathrm{t}+\tau)-\mathrm{u}_{\mathrm{i}}(\mathrm{w}(\mathrm{t}+\tau)+\hat{\gamma})+\mathrm{wN}+\mathrm{rf}^{\prime}\left(\left(\mathrm{e}_{\mathrm{w}} \mathrm{w}_{\mathrm{i}}+\mathrm{e}_{\mathrm{i}}\right) \mathrm{n}+\mathrm{en}_{\mathrm{i}}\right)-\mathrm{u}_{\mathrm{i}} \\
& \left.\mathrm{B}_{\mathrm{r}}=\mathrm{w}_{\mathrm{r}} \mathrm{N}(\mathrm{t}+\tau)-\mathrm{u}_{\mathrm{r}}(\mathrm{w}(\mathrm{t}+\tau)+\hat{\gamma})+\mathrm{f}+\mathrm{rf}^{\prime}\left(\mathrm{e}_{\mathrm{w}} \mathrm{w}_{\mathrm{r}}+\mathrm{e}_{\mathrm{r}}\right) \mathrm{n}+\mathrm{en}_{\mathrm{r}}\right)-\mathrm{u} \hat{\gamma}_{\mathrm{r}}
\end{aligned}
$$

For the subsequent analysis it is assumed that a rise in any tax rate induces a budget surplus, such that $\mathrm{B}_{t}, \mathrm{~B}_{\tau}, \mathrm{B}_{\mathrm{r}}>0$ hold. The change in employment per firm owing to a rise in $\mathrm{r}$ and a fall in $t$, that is the expression in square brackets in (16), assuming a budget neutral tax reform, is given by:

$$
\begin{aligned}
n_{r}+n_{t} \frac{d t}{d r}= & n_{t}\left(A-\frac{B_{r}}{B_{t}}\right)+n_{e} e_{r} \\
= & n_{t} \frac{\left(A w_{t}-w_{r}\right)\left\{N(t+\tau)+r f^{\prime} n e_{w}\right\}}{B_{t}}-n_{t} \frac{[w(t+\tau)+\hat{\gamma}]\left(A u_{t}-u_{r}\right)}{B_{t}} \\
& +n_{t}\left[\frac{A w N-f}{B_{t}}+r f^{\prime} e \frac{A n_{t}-n_{r}}{B_{t}}+r f^{\prime} n \frac{A e_{t}-e_{r}}{B_{t}}-u \frac{A \hat{\gamma}_{t}-\hat{\gamma}_{r}}{B_{t}}\right]+n_{e} e_{r}
\end{aligned}
$$

\footnotetext{
${ }^{7}$ It is assumed for simplicity that there is only one central government budget which is financed by all taxes and SSC and which covers all outlays. Since the number of firms has been normalised to unity, output $\mathrm{f}$ in one firm and output in the whole economy coincide.
} 
To illustrate the impact of the envisaged fiscal reform on the budget in more detail, consider, first, the consequences for the wage level. This wage change alters the contributions of both employers and employees directly as well as the level of effort and, therefore, output. Using equations (8), (11) and (15), the wage effect can be written as:

$$
A w_{t}-w_{r}=\frac{A n_{t} e_{u}-e_{u} n_{r}-\left(e_{w r} w-e_{r}\right)\left(1+e_{u} n_{e}\right)}{D}=\frac{e_{r}-e_{w r} w\left(1+e_{u} n_{e}\right)}{D}
$$

Without further restrictions, especially on the effort function, the budgetary impact owing to the tax induced wage changes is uncertain.

The second effect on the budget results from the change in unemployment which affects contributions and outlays. Using equations (10) and (14), this effect can be expressed as:

$$
A u_{t}-u_{r}=\frac{n_{W}\left(e_{w r} w-e_{r}\right)-e_{w w} w_{e} e_{r}}{D}
$$

If $e_{r}$ and $\left(e_{\mathrm{wr}} \mathrm{W}-\mathrm{e}_{\mathrm{r}}\right)$ can be signed, which is possible unambiguously only for a real benefit system, $e_{r}<0,\left(e_{w r W}-e_{r}\right)>0$, and $A u_{t}-u_{r}<0$ will hold. From equations (16) and (17) it can be gathered that, in this case, the direct unemployment effect of a balanced-budget change in tax rates entails a fall in employment per firm and in aggregate.

The third effect on the budget results from the broadening of the tax base. Since AwN - $\mathrm{f}=$ $-\pi / \eta-\operatorname{swN}(1+t) / \eta<0$ if firms are profitable, from inspection of equation (16) it becomes obvious that the tax base effect unambiguously contributes to a reduction in unemployment.

The fourth channel by which the balanced-budget requirement affects unemployment is via the direct output impact.

$$
\mathrm{rf}^{\prime} \mathrm{e}\left(\mathrm{An_{ \textrm {t } }}-\mathrm{n}_{\mathrm{r}}\right)-\mathrm{rf}^{\prime} \mathrm{ne}_{\mathrm{r}}=-\mathrm{rf}^{\prime} \mathrm{e}_{\mathrm{r}}\left(\mathrm{n}+\mathrm{en}_{\mathrm{e}}\right)
$$

Since the employers' SSC do not have a direct effect on effort for a given wage, that is, since $\mathrm{e}_{\mathrm{t}}=0$ (cf. equation (2)), the rise in the VAT will reduce effort and, thus, output if $\mathrm{e}_{\mathrm{r}}<0$ holds, where use of equations (7) and (8) has been made. From (16) it can then be gathered that this causes a rise in unemployment.

Finally, a change in tax rates can affect the level of benefits. This effect is given by $A \hat{\gamma}_{\mathrm{t}}-\hat{\gamma}_{\mathrm{r}}$, which is zero for $s=0$. However, for $s>0$, the sign of this expression depends on the benefit system (see appendix II).

Summing up, on the one hand, there is a negative employment impact inherent in the shift towards the VAT, captured by $\mathrm{n}_{\mathrm{e}} \mathrm{e}_{\mathrm{r}}$ in equation (17), as long as effort is reduced by a rise in the VAT. On the other hand, the tax base effect raises employment. Moreover, the various other effects tend to have ambiguous consequences. Hence, a general statement with respect to the balanced-budget employment effects of a shift from a payroll tax or employers' SSC to a VAT is not feasible. The ambiguity arises since changes in $\tau$ and $r$ for $s>0$ alter the employees' 
behaviour while variations in $\mathrm{t}$ and in $\mathrm{r}$ for $\mathrm{s}<1$ influence the employers' decisions. Which of these effects dominates is uncertain. However, there is a possibility under which the employment effect of a substitution of a VAT for a payroll tax can be signed, namely if $\left(\mathrm{e}_{\mathrm{wr}} \mathrm{W}-\mathrm{e}_{\mathrm{r}}\right)=$ $\mathrm{e}_{\mathrm{r}}=0$, since this implies $A w_{t}-w_{r}=A u_{t}-u_{r}=0$. This restriction will hold if the VAT is not shifted forward into consumer prices $(s=0)$. This case might also be of great empirical significance since a simultaneous rise in $\mathrm{r}$ and a fall in $\mathrm{t}$ leaves the firm's profits (approximately) unchanged. Therefore, firms need not raise output prices in order to retain the pre-tax reform level of profits. For $s=0$, only the tax base effect remains. This result is captured by:

\section{Proposition 1:}

A balanced-budget shift from a payroll tax to a VAT will increase employment in a shirking framework unambiguously, irrespective of the benefit system, if the VAT is not shifted forward.

In the absence of forward shifting of the VAT, only the firms' reactions to the tax changes determine the employment effect. Since lower tax burdens for the firm raise employment per firm, and because the tax base of the VAT is greater than that of the payroll tax, the shift from the latter to the former reduces unemployment.

\subsection{An Employment-Enhancing Reduction in the Employees' SSC}

Instead of a decline in the employers' SSC and a rise in the VAT, a reduction in the employees' SSC can be combined with an increase in $\mathrm{r}$. The unemployment impact of such a reform is determined by:

$$
\frac{d u}{d r}{ }_{\mid \tau=\tau(r)}=\frac{e_{w w} w\left(n_{r}+n_{\tau} \frac{d \tau}{d r}\right)-n_{w}\left\{e_{w r} w-e_{r}+\left(e_{w \tau} w-e_{\tau}\right) \frac{d \tau}{d r}\right\}}{D}
$$

Since both the employees' and the employers' behaviour are affected by this fiscal reform, imposing a balanced-budget constraint implies similar ambiguities as they have arisen in the analysis of a substitution of a VAT for a payroll tax. Instead of a balanced-budget constraint, subsequently, a restriction on the wage change is imposed which allows for the determination of the employment effect of a shift from employees' SSC to a VAT. Suppose, therefore, that the reform of the fiscal system keeps the net real wage $\mathrm{w}(1-\tau) /(1+\mathrm{sr})$ unchanged at the initial wage. In the present context, this requirement is tantamount to a constant wedge $(1 / \omega)$ between

\footnotetext{
${ }^{8}$ Chang (1995) looks at the welfare maximising combination of a payroll and a commodity tax on one good in a two-sector shirking economy. However, employment effects are not investigated. Moreover, unemployment benefits are normalised to zero such that the commodity tax does not alter the real income of unemployed workers.
} 
labour costs and the net real wage, where $\omega=(1-\tau) /[(1+\operatorname{sr})(1+t)]$, since the payroll tax $t$ is not altered.

For a constant wedge $(\mathrm{d} \omega=0)$, the change in the employees' contributions $\tau$ due to a rise in $\mathrm{r}$, is given by $d \tau / d r=-(1-\tau) s / p$. The term $n_{r}+n_{\tau}(d \tau / d r)$ in equation (19) is then equivalent to $\mathrm{f}^{\prime}(1-\mathrm{s}) /(\eta \mathrm{f} " \mathrm{e})+\mathrm{n}_{\mathrm{e}}\left(\mathrm{e}_{\mathrm{r}}-\mathrm{e}_{\tau} \mathrm{s}(1-\tau) / \mathrm{p}\right)$. Moreover, the expression in curly brackets in (19) collapses to $-\tilde{v}^{\prime}$ bs $/\left(2 p^{2}\right) \leq 0$ for nominal benefits, to $\tilde{v}^{\prime \prime} s(\beta w)^{2} /\left(2 p^{3}\right) \leq 0$ in the case of a constant nominal replacement rate and to zero for real benefit systems (see appendix I). For an unemployment compensation system based on constant real benefits or a constant real replacement rate, the term $\left(e_{r}-e_{\tau} s(1-\tau) / p\right)$ is equal to zero (see appendix III). Hence, the employment effect of a shift from employees' SSC to a VAT is given by:

$$
\frac{\mathrm{du}}{\mathrm{dr}} \mid \mathrm{d} \omega=0, \tau=\tau(\mathrm{r}), \begin{aligned}
\gamma & =\mathrm{b}, \\
\gamma & =\beta \mathrm{w}
\end{aligned}
$$

As long as forward shifting of the VAT is incomplete ( $<1$ ), unemployment will be increased by a rise in the VAT and a fall in employees' SSC for $\mathrm{d} \omega=0$ if benefits are adjusted to changes in consumer prices. If benefits are nominally fixed, $\left(\mathrm{e}_{\mathrm{r}}-\mathrm{e}_{\tau} \mathrm{s}(1-\tau) / \mathrm{p}\right)=\tilde{\mathrm{v}}^{\prime} \mathrm{bs} /\left(2 \mathrm{p}^{2}\right)>0$ will hold. Substituting also for the term in curly brackets in (19) gives rise to:

$$
\frac{d u}{d r \mid d \omega=0, \tau=\tau(r), \gamma=b / p}=\frac{e_{w w} w e(1-s) f^{\prime}}{\eta f^{\prime \prime} e^{2} D}+\frac{\tilde{v}^{\prime} b s}{2 D p^{2}}\left(e_{w w} w n_{e}+n_{w}\right)
$$

Finally, a constant nominal replacement rate implies $\left(\mathrm{e}_{\mathrm{r}}-\mathrm{e}_{\tau} \mathrm{s}(1-\tau) / \mathrm{p}\right)=\tilde{\mathrm{v}}^{\prime} \beta \mathrm{sw} /\left(2 \mathrm{p}^{2}\right)>0$ and:

$$
\frac{d u}{d r}{ }_{\mid d \omega=0, \tau=\tau(r), \gamma=\beta w / p}=\frac{e_{w w} w e(1-s) f^{\prime}}{\eta f^{\prime \prime} e^{2} D}+\frac{w \beta s}{2 D p^{2}}\left(e_{w w} \tilde{v}^{\prime} n_{e}-\frac{n_{w} \tilde{v}^{\prime \prime} \beta w}{p}\right)
$$

Thus, the unemployment effects of a fiscal reform which substitutes the VAT for SSC by employees depend on the benefit system and on the extent to which the VAT is shifted forward.

\section{Proposition 2:}

In a shirking framework, a shift from SSC paid by employees to a VAT, holding constant the wedge between labour costs and the net real wage, will

a) raise unemployment irrespective of the benefit system if the VAT is not shifted forward,

b) raise unemployment in real benefit systems if there is incomplete forward shifting,

c) have no impact on unemployment in real benefit systems if there is full forward shifting,

d) reduce unemployment in nominal benefit systems if there is full forward shifting,

e) have ambiguous employment effects in nominal benefit systems if shifting is incomplete.

Proposition 2 demonstrates that it will be possible to restructure the fiscal system in a manner which allows for an employment enhancing effect of the reform if the shifting parameter $\mathrm{s}$ is 
sufficiently high and if benefits are not indexed to consumer prices. For a given institutional structure of the output market, the longer the time horizon is, the greater the possibility to shift forward increases in the VAT is. Hence, the unemployment reducing impact of the tax reform delineated in Proposition 2 can be argued to occur at least in the long-run. In addition, in comparison to a rise in the VAT which is compensated by a decrease in employers' SSC, an increase in the VAT which induces a reduction in employees' SSC lowers the firm's profits per se. This makes forward shifting more likely than for a substitution of the VAT for a payroll tax. However, an employment expansion will only take place if there is a nominal benefit system. The intuition for Proposition 2 is the following: holding constant the wedge $(1 / \omega)$ implies that the utility from working is not affected by tax changes. Given a constant wedge, there are then two conflicting forces at work owing to the fiscal reform. A higher VAT which is not fully shifted forward reduces the firm's labour demand and raises unemployment. However, if benefits are not indexed to consumer prices, the increase in the VAT will reduce the utility of unemployed workers, raising effort and, thus, labour demand. This reduces unemployment. If benefits are held constant in real terms, the countervailing effect via benefits will not occur and unemployment will unambiguously rise, unless there is full forward shifting of the VAT.

Results c) and d) of Proposition 2 imply (see also Goerke 1999b):

Corollary 2.1

In a shirking framework of efficiency wages in which changes in the VAT are shifted forward completely, a change in the composition of the tax wedge, given its level, affects employment unless unemployment benefits are indexed to the consumer price level.

By assuming full forward shifting, the VAT variation does not cause a direct labour demand effect. Nevertheless, employment changes owing to the alteration in effort. Therefore, the wedge between labour costs and the net real wage might not be an adequate indicator of the employment effects of taxes.

The budgetary impact of an employment enhancing shift from SSC paid by employees to a VAT is, in general, ambiguous. On the one hand, unemployment falls and there is, for example, a broadening of the tax base such that the budget moves into surplus. On the other hand, the main driving force of higher employment is a reduction in wages which, in turn, reduces revenues. However, there is a constellation under which the budgetary effect can be signed. Assume, therefore, full forward shifting and a real benefit system. Unemployment does not change owing to a substitution of employees' SSC by the VAT, holding constant the wedge (Proposition 2, part c). If neither unemployment nor unemployment benefits change, effort will remain the same for the given wage. Full shifting, furthermore, implies that the position of the 
labour demand curve is unaffected by the variation in the VAT. If neither labour demand curve nor shirking constraint are affected by the tax reform, the wage will be constant. Hence, the only budgetary impacts are the revenue enhancing tax base effect and the revenue reducing benefit impact. If the former exceeds the latter, the employees' SSC can be reduced further than required by the constancy of the wedge in order to balance the budget, thus raising aggregate employment (cf. equation (12)). This result, therefore, yields:

\section{Corollary 2.2}

Given a real benefit system and full forward shifting of the VAT, an employment enhancing revenue-neutral (balanced-budget) shift from employees' SSC to a VAT is (will be) feasible in a shirking framework (if the tax base effect exceeds the impact of constant real benefits on the government's budget).

Thus far, it has been assumed that there is no difference between gross and net unemployment benefits since they are not subject to SSC $\tau$. However, in a number of OECD countries unemployment benefits are subject to SSC or to income taxes (OECD 1988, 1991, 1993, Goerke 1999b, Koskela and Schöb 1999). In countries in which this is the case, Proposition 2 and its Corollaries are no longer applicable and the employment effects of a shift from employees' SSC to the VAT cannot be determined.

\subsection{A Reduction in Social Security Contributions Shared by Employer and Employees}

In many (European) countries, SSC are shared by employers and employees. Often both sides to the labour contract pay half of the contributions (see OECD 1993). If this notion of equal shares in the financing of social security is strong, a reduction in the contributions of just one party, as it has been analysed in the previous sub-sections, may not be politically feasible. Hence, the question arises as to what the employment consequences of a shift from SSC shared by employers and employees to a VAT are. If the equal sharing rule for SSC is preserved, the fall in $t$ owing to a rise in $r$, and the concomitant reduction in $\tau$ will be the same $(d \tau=d t)$. Since $\Psi_{\mathrm{t}}=0$, the unemployment impact of such a tax reform is found to be:

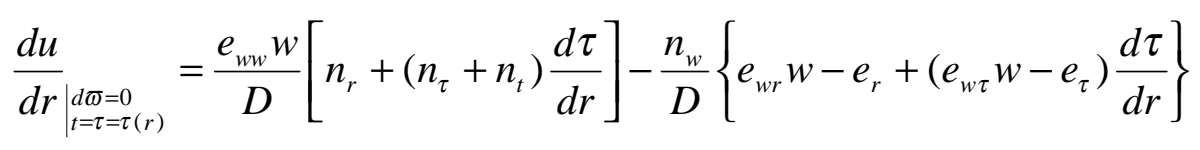

Suppose that, in addition to $\mathrm{d} \tau / \mathrm{dt}=1$, the ratio $(1 / \bar{\omega})$ of the gross nominal wage to the net real wage, $\Phi=(1-\tau) /(1+\mathrm{sr})$ is held constant. It has been shown in Section 5.2 that the assumption of $d \omega=0$ for $d t=0$, which is equivalent to $d \Phi=0$, implies that the expression in curly 
brackets in (20) is non-positive. Thus, replacing $\mathrm{n}_{\mathrm{r}}, \mathrm{n}_{\tau}, \mathrm{n}_{\mathrm{t}}$, and $\mathrm{A}$ in accordance with equations (7) to (9), and using $\mathrm{d} \Phi=0$, a sufficient condition for unemployment to fall, owing to a reduction in SSC by employers and employees and a rise in the VAT, is:

$$
n_{r}+\left(n_{\tau}+n_{t}\right) \frac{d \tau}{d r}=n_{t}\left[\frac{(1-s)(1+t)}{1-r+r s}-\frac{(1-t) s}{1+s r}\right]+n_{e}\left\{e_{r}-\frac{1-\tau}{p} s e_{\tau}\right\}>0
$$

Since $\left(e_{r}-e_{\tau} s(1-\tau) / p\right)$ will either be zero for real benefits or positive for nominal benefit systems if $\mathrm{d} \Phi=0$ (see appendix III) a sufficient condition for an employment enhancing shift from SSC to the VAT is that the term in square brackets in (21) is positive. Solving for s in this expression yields a minimum value for the extent of shifting to induce a positive employment effect and gives rise to:

\section{Proposition 3:}

Irrespective of the nature of the benefit system, a sufficient condition for a shift from SSC shared equally by employees and employers to a VAT to reduce unemployment, holding constant the difference between gross nominal and the net real wage, is that the extent of forward shifting of the VAT exceeds a critical value ${ }^{*}$, where:

$$
\mathrm{s}^{*}=\frac{\sqrt{\mathrm{r}^{2}+2 \mathrm{rt}+1}+\mathrm{r}-1}{2 \mathrm{r}}
$$

Using VAT rates between $15 \%$ and $30 \%$, it can be shown that $\mathrm{s} *$ is fairly invariant to different levels of SSC. For SSC rates $\mathrm{t}=\tau$ of $5 \%$, for example, $\mathrm{s}^{*}$ varies between 0.562 and 0.597 , depending on the VAT rate $r$. If the contribution rates are $20 \%, r=0.15$ will imply s* $=0.635$ and $r=0.3$ will entail $s^{*}=2 / 3$. Since the critical value of $s$ is calculated on the basis of a sufficiency requirement, in systems with nominally fixed unemployment compensation, a lower value of $\mathrm{s}^{*}$ guarantees a positive employment effect.

The intuition for Proposition 3 is that a sufficient degree of forward shifting limits the adverse labour demand curve effects. The imposition of a constant ratio between the gross nominal and the net real wage keeps the utility from working unchanged for a given wage. Since SSC by employers are reduced, there is a positive employment impact. Hence, in an efficiency wage economy in which SSC are shared equally by employers and employees, an employment enhancing shift from these contributions to a VAT will, in general, be feasible if the government does not insist on a balanced budget.

\footnotetext{
${ }^{9}$ If the wedge $(1 / \omega)$ were held constant, instead of imposing $\mathrm{d} \Phi=0$, a given rise in the VAT would require a less pronounced reduction in $\tau$ since $t$ would also fall. Hence, the subsequent argument would no longer apply.
} 


\section{Conclusions}

In order to alleviate the European unemployment problem it is often suggested in the political debate to reduce labour costs. Since social security contributions have increased strongly in many OECD countries, the desire to lower labour costs is often tantamount to the request of a reduction in these contributions. In order to compensate for the ensuing loss in revenues, a rise in the value-added tax has been suggested. In this paper, it has been shown in the context of a shirking model of efficiency wages that such a tax reform will only reduce unemployment under specific conditions. More precisely, a balanced-budget shift from a payroll tax to a value-added tax will increase employment if the value-added tax is not shifted forward. If the value-added tax increase raises consumer prices, positive employment effects of a shift from a payroll to a value-added tax can depend on unemployment benefits being defined in nominal terms. A substitution of a value-added tax for social security contributions levied on employees will reduce unemployment if, first, the wedge is kept constant, second, the valueadded tax increase is shifted forward completely and, third, benefits are not indexed to consumer prices. Moreover, it has been shown that the composition of the tax wedge can affect employment. If social security contributions are shared equally by employers and employees, a sufficient condition for a shift from social security contributions to a value-added tax to raise employment, irrespective of the benefit system and holding constant the difference between the gross nominal and net real wage, will be that changes in the value-added tax are shifted forward into consumer prices by at least two-thirds, assuming plausible values for taxes and contribution rates. All these predictions are based on the presumption that variations in employees' contributions do not affect unemployment benefits directly.

These findings can also contribute to an evaluation of the reform probably taking place in Germany in the future. Namely, a substitution of taxes on energy use for contributions to the quasi-mandatory pension system. Since social security contributions are shared equally by employers and employees in Germany, Proposition 3 states that the increase in the taxes on energy must be shifted forward to a sufficient degree to warrant a rise in employment, provided that net real wages do not decline. However, a tax on energy use presumably affects different households in a much more diverse manner than a uniform value-added tax, since only one category of goods is taxed additionally. Moreover, the firms' reductions in labour costs and the increases in expenditure for energy will vary in accordance with the relative intensity of the inputs labour and energy. Thus, the employment effects of a substitution of a tax on energy use for contributions to the pension system in an efficiency wage economy are more ambiguous than Proposition 3 suggests. Moreover, unemployment benefits are indexed to net wages and, therefore, directly influenced by variations in the employees' contribution 
rates to the pension system. This feature of the German unemployment benefit system creates further uncertainties. Since other models of the labour market which can explain unemployment are likely to yield similarly ambiguous predictions, the reform probably taking place in Germany cannot be argued to raise the number of jobs on the basis of microeconomic models of unemployment.

In conclusion, it should be mentioned that the above analysis has omitted a number of aspects which are usually argued to affect the performance of a value-added tax in comparison to social security contributions and which will, therefore, also have a bearing on a substitution of taxes on energy use for contributions to the pension system. First, the labour supply decision has not been endogenised such that potential disincentive effects of social security contributions have been excluded. However, a value-added tax also worsens the trade-off between work and leisure. Second, a value-added tax broadens the tax base because of income from wealth and capital. This tax base impact has not played a role in the model. Third, capital formation, or more generally savings decisions and growth aspects, have not been considered. Fourth, it is usually maintained that tax evasion is a more severe problem for earnings-related taxes than for value-added taxes. However, for social security contributions, which often imply a direct entitlement to health or retirement schemes, the issue of tax evasion or avoidance might be less severe than for income taxes. Finally, the economy under investigation is a closed one. In an open economy, forward shifting of VAT increases might be possible to a lesser degree than in a closed economy, or not at all, since competition by foreign firms which have not experienced the tax increase prevents higher prices if the value-added tax is collected at the origin. In the EU, however, the destination principle for the value-added tax ensures that variations in this tax apply to imported goods, as well. Therefore, the closed economy assumption is unlikely to affect policy conclusions in a European context, unless cross-border shopping activities have a substantial impact. 


\section{Appendix}

I. Shirking Constraint, VAT, and Employees' SSC

The derivative of $\Psi$ (cf. equation (5)) with respect to the VAT is given by $\Psi_{\mathrm{r}}=\mathrm{e}_{\mathrm{wr}} \mathrm{W}-\mathrm{e}_{\mathrm{r}}$. The sign of this expression depends on the unemployment benefit system.

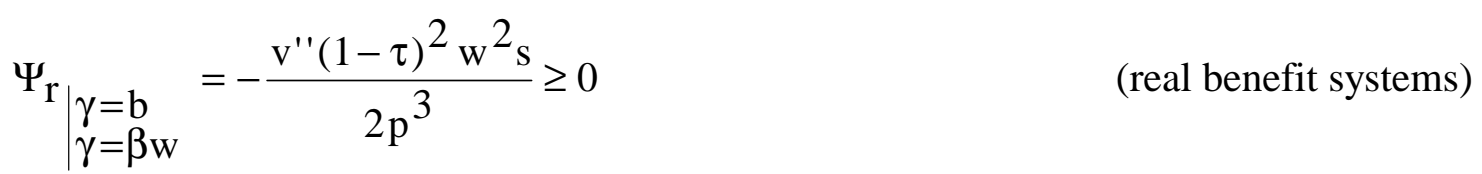

$\Psi_{\mathrm{r} \mid \gamma=\mathrm{b} / \mathrm{p}}=-\mathrm{s} \frac{\mathrm{v}^{\prime \prime}(1-\tau)^{2} \mathrm{w}^{2}+\tilde{\mathrm{v}}^{\prime} \mathrm{bp}}{2 \mathrm{p}^{3}} \quad$ (nominal benefits)

$\Psi_{\mathrm{r} \mid \gamma=\beta \mathrm{w} / \mathrm{p}}=-\mathrm{sw} \frac{\mathrm{v}^{\prime \prime}(1-\tau)^{2} \mathrm{w}-\tilde{\mathrm{v}}^{\prime \prime} \beta^{2}}{2 \mathrm{p}^{3}} \quad$ (nominal replacement rate)

The derivative of the shirking constraint with respect to $\tau$ is independent of the benefit system.

$\Psi_{\tau}=\mathrm{e}_{\mathrm{w} \tau} \mathrm{w}-\mathrm{e}_{\tau}=-\frac{\mathrm{v}^{\prime \prime}(1-\tau) \mathrm{w}^{2}}{2 \mathrm{p}^{2}}>0$

II: The sign of $\left(\mathrm{A} \hat{\gamma}_{\mathrm{t}}-\hat{\gamma}_{\mathrm{r}}\right)$

a) Nominal benefits $(\gamma=b / p, \hat{\gamma}=b)$

$\hat{\gamma}_{\mathrm{r}}=\hat{\gamma}_{\mathrm{t}}=0 \Rightarrow\left(\mathrm{A} \hat{\gamma}_{\mathrm{t}}-\hat{\gamma}_{\mathrm{r}}\right)=0$

b) Nominal replacement rate $(\gamma=\beta \mathrm{w} / \mathrm{p}, \hat{\gamma}=\beta \mathrm{w})$

$\hat{\gamma}_{\mathrm{r}}=\beta \mathrm{w}_{\mathrm{r}}, \hat{\gamma}_{\mathrm{t}}=\beta \mathrm{w}_{\mathrm{t}} \Rightarrow\left(\mathrm{A} \hat{\gamma}_{\mathrm{t}}-\hat{\gamma}_{\mathrm{r}}\right)=\beta\left(\mathrm{Aw}_{\mathrm{t}}-\mathrm{w}_{\mathrm{r}}\right)=\beta\left[\mathrm{e}_{\mathrm{r}}-\mathrm{e}_{\mathrm{wr}} \mathrm{w}\left(1+\mathrm{e}_{\mathrm{u}} \mathrm{n}_{\mathrm{e}}\right)\right] / \mathrm{D}$

using (18), where D is defined in (10). If $\mathrm{s}=0, \mathrm{e}_{\mathrm{wr}} \mathrm{W}-\mathrm{e}_{\mathrm{r}}=\mathrm{e}_{\mathrm{r}}=\mathrm{e}_{\mathrm{wr}}=0$ will apply. Hence,

$A w_{t}-w_{r}=A \hat{\gamma}_{t}-\hat{\gamma}_{r}=0$

c) Real benefits $(\gamma=b, \hat{\gamma}=b p=b(1+r s))$

$\hat{\gamma}_{\mathrm{r}}=\mathrm{bs}, \hat{\gamma}_{\mathrm{t}}=0 \Rightarrow\left(\mathrm{A} \hat{\gamma}_{\mathrm{t}}-\hat{\gamma}_{\mathrm{r}}\right)=-\mathrm{bs} \leq 0$

d) Real replacement rate $(\gamma=\beta \mathrm{w}, \hat{\gamma}=\beta \mathrm{wp}=\beta \mathrm{w}(1+\mathrm{rs}))$ :

$\hat{\gamma}_{\mathrm{r}}=\beta\left(\mathrm{w}_{\mathrm{r}} \mathrm{p}+\mathrm{ws}\right), \hat{\gamma}_{\mathrm{t}}=\beta \mathrm{pw}_{\mathrm{t}}$

$\Rightarrow\left(\mathrm{A} \hat{\gamma}_{\mathrm{t}}-\hat{\gamma}_{\mathrm{r}}\right)=\beta\left(\mathrm{p}\left(\mathrm{Aw}_{\mathrm{t}}-\mathrm{w}_{\mathrm{r}}\right)-\mathrm{ws}\right)=\beta \mathrm{p}\left[\mathrm{e}_{\mathrm{r}}-\mathrm{e}_{\mathrm{wr}} \mathrm{w}\left(1+\mathrm{e}_{\mathrm{u}} \mathrm{n}_{\mathrm{e}}\right)\right] / \mathrm{D}-\beta \mathrm{ws}$. Again, $\mathrm{s}=0$

implies $\mathrm{e}_{\mathrm{r}}=\mathrm{e}_{\mathrm{Wr}}=0$ and, hence, $\left(\mathrm{A} \hat{\gamma}_{\mathrm{t}}-\hat{\gamma}_{\mathrm{r}}\right)=0$.

III: Change in Effort Owing to a Rise in the VAT 
For a given wage, an increase in the VAT reduces effort unambiguously, unless benefits are nominally fixed. Note, moreover, that $\mathrm{e}_{\mathrm{r}}=-\mathrm{v}^{\prime}(\mathrm{w}) /(2 \mathrm{p})$.

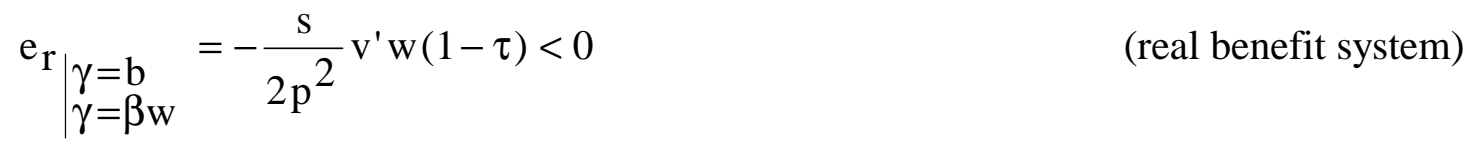

Hence, $e_{\mathrm{r}}-\mathrm{e} \tau \mathrm{s}(1-\tau) / \mathrm{p}=0$ holds.

$\mathrm{e}_{\mathrm{r}_{\mid \gamma=b / p}}=-\mathrm{s} \frac{\mathrm{v}^{\prime} \mathrm{w}(1-\tau)-\tilde{\mathrm{v}}^{\prime} \mathrm{b}}{2 \mathrm{p}^{2}}$

(nominal benefits).

This implies $e_{r}-e_{\tau} s(1-\tau) / p=\tilde{v}^{\prime} b s /\left(2 p^{2}\right)>0$.

$\mathrm{e}_{\mathrm{r}}{ }_{\gamma=\beta \mathrm{w} / \mathrm{p}}=-\frac{\mathrm{s}}{2 \mathrm{p}^{2}}\left[\mathrm{v}^{\prime} \mathrm{w}(1-\tau)-\tilde{\mathrm{v}}^{\prime} \beta \mathrm{w}\right]=-\frac{\mathrm{swe}_{\mathrm{W}}}{\mathrm{p}}<0 \quad$ (nominal replacement rate).

Therefore, $e_{r}-e_{\tau} s(1-\tau) / p=\tilde{v}^{\prime} \beta s w /\left(2 p^{2}\right)>0$.

\section{References}

Bovenberg, A. Lars and Frederick van der Ploeg (1994), Effects of the Tax and Benefit System on Wage Formation and Unemployment, Mimeo, Tilburg University.

Carter, Thomas J. (1992), Labor Subsidies and Just-Cause Employment Laws in an Efficiency Wage Model, Southern Economic Journal, Vol. 59, 49-57.

Chang, Ching Huei (1995), Optimum Taxation in an Efficiency Wage Model, Southern Economic Journal, Vol. 62, 428-39.

Devine, Theresa J. and Nicholas M. Kiefer (1991), Empirical Labor Economics, New York and Oxford: Oxford University Press.

EU (Commission of the European Communities) (1993), White Paper on Growth, Competitiveness, Employment: the Challenges and Ways Forward into the 21st Century, COM (93)700 final.

Fehr, Ernst (1991), Wages and Labour Demand: A Note, Journal of Institutional and Theoretical Economics, Vol. 147, 539-46.

Goerke, Laszlo (1997), Taxes in an Efficiency Wage Economy in the Short-run and in the Long-run, Finanzarchiv (Neue Folge), Vol. 54, 447-470.

Goerke, Laszlo (1999a), Efficiency Wages and Taxes, Australian Economic Papers, Vol. 38, 131-142.

Goerke, Laszlo (1999b), The Wedge, forthcoming: The Manchester School.

Hoel, Michael (1990), Efficiency Wages and Income Taxes, Journal of Economics, Vol. 51, 8999.

Hoon, Hian Teck and Edmund S. Phelps (1996), Payroll Taxes and VAT in a Labor-Turnover Model of the 'Natural Rate', International Tax and Public Finance, Vol. 3, 369-83.

Koskela, Erkki and Ronnie Schöb (1999), Alleviating Unemployment: The Case for Green Tax Reforms, forthcoming: European Economic Review. 
Layard, Richard, Nickell, Stephen and Richard Jackman (1991), Unemployment -

Macroeconomic Performance and the Labour Market, Oxford: Oxford University Press.

Lin, Chung-cheng and Ching-chong Lai (1997), The Solow Condition in an Efficiency Wage Model with Overtime Work, Australian Economic Papers, Vol. 36, 342-350.

OECD (1988), Employment Outlook, September, Chapter 4, Description of Unemployment Benefit Systems in OECD Countries, Paris.

OECD (1991), Employment Outlook, July, Chapter 7: Unemployment Benefit Rules and Labour Market Policy, Paris.

OECD (1993), Taxation in OECD Countries, Paris.

OECD (1995), The OECD Jobs Study - Taxation, Employment and Unemployment, Paris.

Pemberton, James (1992), Taxation and Wage Bargaining, Economic Record, Vol. 68, 318-327.

Pencavel, John H. (1991), Labor Markets under Trade Unionism, Blackwell: Cambridge.

Petrucci, Alberto (1994), Wage, Taxation, and Turnover Costs, Public Finance/ Finances Publiques, Vol. 49, 200-211.

Pflüger, Michael (1997), On the Employment Effects of Revenue-Neutral Tax Reforms, Finanzarchiv (Neue Folge), Vol. 54, 430-446.

Pisauro, Guiseppe (1991), The Effect of Taxes on Labour in Efficiency Wage Models, Journal of Public Economics, Vol. 46, 329-45.

Pissarides, Christopher A. (1998), The Impact of Employment Tax Cuts on Unemployment and Wages; The Role of Unemployment Benefits and Tax Structure, European Economic Review, Vol. 42, 155-183.

Shapiro, Carl and Joseph E. Stiglitz (1984), Equilibrium Unemployment as a Worker Discipline Device, American Economic Review, Vol. 74, 433-444.

Solow, Robert M. (1979), Another Possible Source of Wage Stickiness, Journal of Macroeconomics, Vol. 1, 79-82.

Zoega, Gylfi (1997), Public Consumption and Unemployment, Scottish Journal of Political Economy, Vol. 44, 269-79. 